\title{
Use of photocatalysis for conversion of harvested rainwater as an alternative source into drinking water
}

\author{
Ab Aziz N.A.B., Palaniandy P. ${ }^{*}$, Abdul Aziz H. and Aljuboury D.A.D. \\ School of Civil Engineering, Engineering Campus, Universiti Sains Malaysia, 14300 Nibong Tebal, Penang, Malaysia \\ Received: 22/10/2017, Accepted: 22/01/2018, Available online: 09/05/2018 \\ *to whom all correspondence should be addressed: e-mail: cepuganeshwary@usm.my
}

\begin{abstract}
The aim of this study is to investigate the performance of solar photo-catalyst of titanium oxide $\left(\mathrm{TiO}_{2} / \mathrm{Solar}\right)$ process to treat rainwater. The polycyclic aromatic hydrocarbons (PAHs) and organochlorine pesticides (OCPs) in rainwater were chosen to be investigated in this study. The rainwater characterization results revealed that PAHs (NAP, FLT, and PYR) were more predominant in industrial and urban residential areas, whereas OCPs (LIN and DDT) were found to contaminate more on the agricultural and rural residential areas. Central composite design with response surface methodology was used to evaluate the relationships between operating variables for $\mathrm{TiO}_{2}$ dosage, $\mathrm{pH}$, and and initial concentration to identify the optimum operating conditions. Quadratic models for FLT, PYR, LIN, and DDT prove to be significant with low probabilities $(<0.0001)$. The obtained optimum conditions included $\mathrm{pH}$ (7), $\mathrm{TiO}_{2}$ concentration $(1.54 \mathrm{~g} / \mathrm{L})$, and initial concentration $(125 \mu \mathrm{g} / \mathrm{L})$. The maximum removal rates were for FLT (88\%), PYR (90\%), LIN (66\%), and DDT (79\%). The polycyclic aromatic hydrocarbons (PAHs) and organochlorine pesticides (OCPs) removal rates correspond well with the predicted models. The photo-degradation process of FLT, PYR, LIN, and DDT followed pseudo first order rate of reaction through $\mathrm{L}-\mathrm{H}$ kinetic model. The proposed treatment process achieved higher degradation efficiencies for FLT, PYR, LIN, and DDT.
\end{abstract}

Keywords: $\mathrm{PAHs}, \mathrm{OCPs}, \mathrm{TiO}_{2}, \mathrm{pH}, \mathrm{RSM}$, quadratic, UV source

\section{Introduction}

Water shortage is becoming the number one problem in the world today. The increasing demand of a growing population, had given more problems in water shortage (Sazakli et al., 2007). Moreover, water scarcity is strongly connected to the problem of water quality. Urban development and climate conditions had deteriorated the quality of water and in some cases, make it unsafe for consumption (Abdulla and Al-Shareef, 2009). Rainwater harvesting may increase local water resources quantity, store and regulate the flood peak flow or to reduce runoff, improve the urban water cycle and the ecological environment (Wang et al., 2009).
One of the important benefits of rainwater harvesting is to reduce the dependence and demand of public water supply which is treated from river. In addition, this will also act as an additional water supply for fire protection or emergency use, increase the ground water table through artificial recharge and contribute in overcoming the shortage of water during extreme droughts (NAHRIM, 2007). However, harvested rainwater might be polluted with the atmospheric pollutants accumulated on the roofs and the ones exist in the rain, as well as the catchment surface materials itself (Kim et al., 2005). In a complete system of rainwater collection, treatment is necessary to kill some emerging pollutants that exist in the rainwater such as polycyclic aromatic hydrocarbons (PAHs) and organochlorine pesticides (OCPs).

These compounds, even present at very low concentrations, are very persistent and toxic, which happen to degrade very slowly in the environment. PAHs and OCPs have been listed by USEPA as the persistent organic pollutants (POPs), as a consequence of their potential carcinogenic, mutagenic, tetratogenic effects on organisms, including human beings (Rubio-Clemente et al., 2014). Application of heterogeneous photocatalysis has gained wide attention due to its effectiveness in degrading organic compounds (Chong et al. 2010; Ahmed et al. 2011; Robertson et al., 2012). Photocatalysis is based on the absorption of a photon from a UV source on a semiconductor surface, mostly used is titanium dioxide $\left(\mathrm{TiO}_{2}\right)$, to convert the organic compounds into harmless end products (Robertson et al., 2012).

The basic principle of semiconductor photocatalysis relies on the formation of an electron-hole pair upon the absorption of a photon with energy equal or bigger than the semiconductor's band gap (Robertson et al., 2012). The electron and hole can recombine, releasing the absorbed light energy as heat, and this will prevent the occurrence of redox reactions. In order to avoid recombination, a continuous supply of oxygen radical species must be provided throughout the process (Bahnemann, 2004).

Hydroxide radicals and superoxide ions can rapidly attack pollutants at the surface, and possibly in solution as well. Both of these substances (hydroxyl radicals and superoxide ions) are the most important products formed in $\mathrm{TiO}_{2}$ 
photocatalysis. Since this process breaks down the contaminant molecules continuously, no residue of the original material remains and therefore no sludge requiring disposal is produced. The $\mathrm{TiO}_{2}$ particle itself is unchanged and no consumable chemicals are required (Al-Rasheed, 2005). Equations below show the series of reactions that occur in the photocatalytic treatment process:

1. Formation of electron-hole pair: $\mathrm{TiO}_{2}$ $\stackrel{\text { hv }}{\rightarrow} \mathrm{e}_{\mathrm{cb}}^{-}\left(\mathrm{TiO}_{2}\right)+\mathrm{h}_{\mathrm{vb}}^{+}\left(\mathrm{TiO}_{2}\right)$

2. Formation of hydroxyl radicals: $\mathrm{TiO}_{2}\left(\mathrm{~h}_{\mathrm{vb}}^{+}\right)+$ $\mathrm{H}_{2} \mathrm{O}_{\mathrm{ads}} \rightarrow \mathrm{TiO}_{2}+\mathrm{HO}_{\mathrm{ads}}+\mathrm{H}^{+}$

$$
\mathrm{TiO}_{2}\left(\mathrm{~h}_{\mathrm{vb}}^{+}\right)+\mathrm{HO}_{\mathrm{ads}} \rightarrow \mathrm{TiO}_{2}+\mathrm{HO}_{\mathrm{ads}}
$$

3. Formation of superoxide anions: $\mathrm{TiO}_{2}\left(\mathrm{e}_{\mathrm{cb}}^{-}\right)+\mathrm{O}_{2 \text { ads }}+\mathrm{H}^{+} \rightarrow \mathrm{TiO}_{2}+\mathrm{HO}_{2} \rightarrow \dot{\mathrm{O}}_{2}^{-}+\mathrm{H}^{+}$

The objectives of this research work are to study the characteristic and provide the baseline data of the possible micro-pollutants present in rainwater, investigate the operational factors that control the mechanism of heterogeneous photocatalyst $\left(\mathrm{TiO}_{2}\right)$ process in harvested rainwater treatment, and

The aims of this study are as follows:

- To investigate the performance of the performance of solar photo-catalyst of titanium oxide $\left(\mathrm{TiO}_{2} /\right.$ Solar $)$ process in rainwater treatment.

- To evaluate the performance of employing this process by a CCD with RSM to degradation of FLT, PYR, LIN, and DDT from the rainwater.
- To evaluate the statistical relationships among operating variables (such as $\mathrm{TiO}_{2}$ dosage, $\mathrm{pH}$, and initial concentration) and the responses, which FLT, PYR, LIN, and DDT removal efficiencies are selected as the responses for optimization.

- To determine the optimum operational conditions of the proposed method.

- To study the kinetic mechanism involved in the solar photo-catalyst of titanium oxide $\left(\mathrm{TiO}_{2} / \mathrm{Solar}\right)$ process.

- To compare the proposed method with the previous works.

\section{Materials and method}

\section{Sampling and characterization}

Samples of the rainwater were collected from 5 different points comprised of urban residential, rural residential, agricultural, industrial, and open space areas during the period May 2015 until May 2016. Samples were transferred to the laboratory and stored under refrigeration (4 WC) until use. Samples were characterized before the experiments to obtain their chemical and physical properties. The rainwater characterization was determined by the quantification of fluoranthene, pyrene, lindane, and DDT according to Standard Methods for the Examination of Water and Waste Water (2005). General characteristics of the rainwater are summarized in Table 1.

Table 1. Characterization of actual rainwater sample

\begin{tabular}{|c|c|c|c|c|c|c|}
\hline \multirow{2}{*}{\multicolumn{2}{|c|}{ Sampling Point }} & \multicolumn{5}{|c|}{ Concentration Range in $\mu \mathrm{g} / \mathrm{L}$ [Average] } \\
\hline & & NAP & FLT & PYR & LIN & DDT \\
\hline \multirow{4}{*}{ Residential } & \multirow{2}{*}{ Urban } & $B L Q-68.43$ & BLQ - 73.30 & BLQ - 75.12 & $B L Q-57.13$ & $B L Q-44.00$ \\
\hline & & [10.03] & [12.05] & [16.16] & {$[5.95]$} & [4.03] \\
\hline & \multirow{2}{*}{ Rural } & BLQ - 57.89 & $B L Q-45.80$ & $B L Q-39.45$ & BLQ - 77.22 & $B L Q-83.30$ \\
\hline & & {$[6.87]$} & [7.83] & [7.34] & {$[9.05]$} & {$[8.61]$} \\
\hline \multirow{2}{*}{\multicolumn{2}{|c|}{ Industrial }} & BLQ - 89.27 & BLQ - 82.02 & $B L Q-85.40$ & BLQ - 67.90 & BLQ - 60.27 \\
\hline & & [20.79] & [21.99] & [23.58] & {$[8.92]$} & [6.14] \\
\hline \multirow{2}{*}{\multicolumn{2}{|c|}{ Agricultural }} & BLQ - 6.90 & BLQ - 8.18 & $B L Q-10.42$ & $B L Q-58.70$ & $B L Q-50.21$ \\
\hline & & {$[0.96]$} & [1.41] & [1.69] & {$[9.63]$} & [9.06] \\
\hline \multirow{2}{*}{\multicolumn{2}{|c|}{ Open Space }} & BLQ - 20.40 & BLQ - 25.92 & BLQ - 32.11 & BLQ - 60.00 & BLQ - 37.80 \\
\hline & & {$[2.47]$} & {$[3.53]$} & {$[3.79]$} & {$[4.46]$} & {$[4.24]$} \\
\hline
\end{tabular}

${ }^{*} B L Q=$ below limit quantification ( $\left.<0.04 \mathrm{ng} / \mathrm{L}\right)$

\subsection{Materials and Reagents}

Analytical standards of fluoranthene (FLT), pyrene (PYR), lindane $(\gamma-\mathrm{HCH})$, and DDT were purchased from SigmaAldrich (Steinhelm, Germany) with a purity ranged of $98.6 \%, 97.5 \%, 99.8 \%$ and $98.7 \%$, respectively. Methanol and dichloromethane used as the organic solvent were of the analytical residue grade and obtained from Systerm. Titanium dioxide in the anatase form, has a $99.5 \%$ purity with mean particle size of $30 \mathrm{~nm}$ and surface area of 50 $\mathrm{m}^{2} / \mathrm{g}$, was supplied from R\&M Marketing, Essex, U.K.

\subsection{GC-MS Analysis}

The quantification of fluoranthene, pyrene, lindane and DDT was conducted using an Agilent 6890N Series GC System coupled with Agilent 5973 Inert Mass Selective
Detector. The column used was Agilent HP-5MS fused capillary column (USA) with description as follows: 30.0 $\mathrm{m} \times 250 \mu \mathrm{m} \times 0.25 \mu \mathrm{m}$. The carrier gas was helium. The inlet temperature was $300{ }^{\circ} \mathrm{C} .1 \mu \mathrm{L}$ of the sample was injected into the GC. The temperature program was as follows: initial oven temperature was held at $70{ }^{\circ} \mathrm{C}$ for $2 \mathrm{~min}$, and ramped to $290{ }^{\circ} \mathrm{C}$ at a rate of $15{ }^{\circ} \mathrm{C} / \mathrm{min}$. The mass spectrometer was operated under electron impact (EI), choosing $70 \mathrm{eV}$ as the electron energies, while the ion source temperature was set to $230{ }^{\circ} \mathrm{C}$. Selective ion monitoring (SIM) mode was used for monitoring the analytes. Quantification ion for both fluoranthene and pyrene is 202, while for lindane and DDT are 181 and 235, respectively. All four compounds were identified by comparing the retention time (chromatographic column) 
and mass spectra (mass detector) with the standards (full scan mode).

\subsection{Experimental procedure}

Stock solutions were prepared by dissolving the powdered standard of fluoranthene, pyrene, lindane and DDT, with a mixture of dichloromethane and methanol, which then were stored at $4{ }^{\circ} \mathrm{C}$. Synthetic rainwater was then prepared by diluting a certain amount of stock standard solutions with deionized water to a $15 \mathrm{~L}$ volume of the mixture. The initial concentration for all compounds in the synthetic rainwater were the same and tested from 50 to $200 \mu \mathrm{g} / \mathrm{L}$. Adequate amount of $\mathrm{TiO}_{2}$ was added to the aqueous solution. The suspension was then exposed to natural sunlight using Compound Parabolic Collecting Reactor (CPCR) under different experimental conditions, such as duration of treatment exposure, $\mathrm{pH}$, dosage of titanium dioxide, and pollutant initial concentration. The solution was sampled after 30 minutes of irradiation time and delivered to the laboratory for the analytical testing purposes. In order to quantify the concentration of pollutants, the efficiency test was carried out to determine the effectiveness of the photocatalysis treatment process in degrading PAHs and OCPs. The degradation percentage was defined as in Equation 1 below:

$$
\text { Degradation \% }=\frac{\mathrm{C}_{0}-\mathrm{C}_{\mathrm{e}}}{\mathrm{C}_{\mathrm{o}}} \times 100
$$

Where $C_{o}$ is the initial concentration and $C_{e}$ is the final concentration of the compound.

\section{Results and discussion}

\subsection{Effects of Operating Factors}

\subsubsection{Effect of $\mathrm{TiO}_{2}$ Concentration}

Titanium dioxide is able to promote the interaction between hydroxyl radicals and the pollutants. However, appropriate amount of the catalyst should be applied to avoid undesirable effects of photocatalytic decontamination process. Figure 1 illustrates the effect of $\mathrm{TiO}_{2}$ concentration towards the photocatalytic degradation of NAP, FLT, PYR, LIN, and DDT. From the graph, it can be observed that all pollutants show similar trends of photodegradation, except NAP, which achieved $100 \%$ removal for all concentrations of $\mathrm{TiO}_{2}$. This observation concludes that $\mathrm{TiO}_{2}$ loading did not significantly affect the degradation rate of NAP in the photocatalysis process.

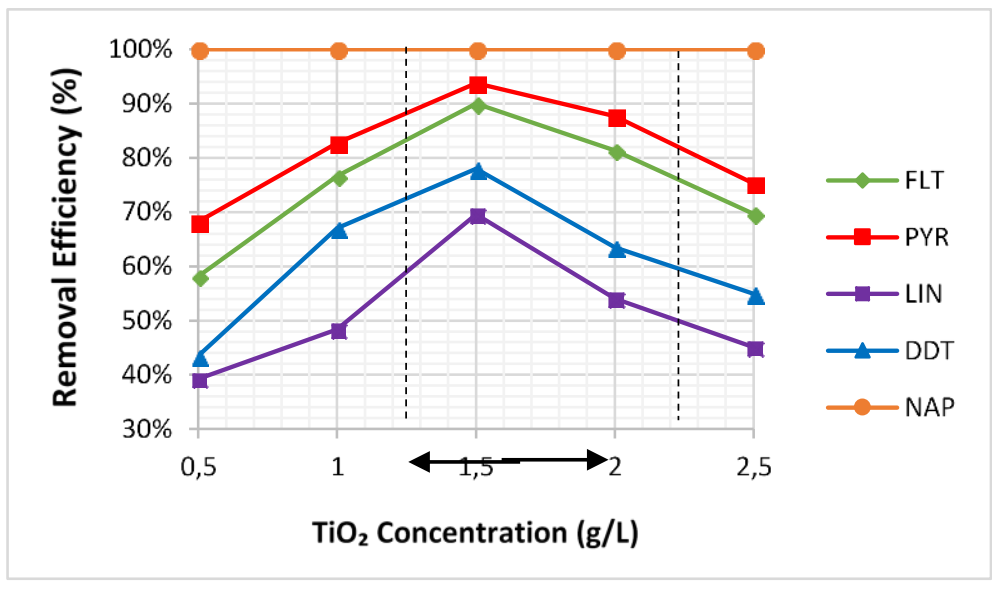

Figure 1. Effect of $\mathrm{TiO}_{2}$ concentration towards the photocatalytic degradation of NAP, FLT, PYR, LIN, and DDT

It was demonstrated that the degradation rate increases with the increment of $\mathrm{TiO}_{2}$ concentration, from $0.5 \mathrm{~g} / \mathrm{L}$ up to a maximum value of $1.5 \mathrm{~g} / \mathrm{L} \mathrm{TiO}_{2}$ concentration. It should be pointed out that the catalyst loading affects the number of active sites on photocatalyst and the penetration of UV light through the suspension (Bibak and Aliabadi, 2014). As the $\mathrm{TiO}_{2}$ concentration increases, the number of the active sites on the $\mathrm{TiO}_{2}$ surface which in turn increases the number of hydroxyl radicals formed consequently leading to enhanced degradation rates of pollutants (Reza et al., 2015).

However, further increment in the $\mathrm{TiO}_{2}$ concentration from $1.5 \mathrm{~g} / \mathrm{L}$ to $2.5 \mathrm{~g} / \mathrm{L}$ then contributed to a reduction in the degradation percentage of FLT, PYR, LIN, and DDT. This result, following heterogeneous regime, are likely due to a saturation effect from the high catalyst amount that causes turbidity, which then impedes the penetration of the sunlight photons from entering the aqueous solution
(Malato et al., 2009). Such condition occurs when the availability of the active sites is more than the light penetration itself, which would create a screening effect and opacity of the suspension (Pang et al., 2009; Lair et al., 2008; Begum and Gautam, 2011). Thus, excess dosage of $\mathrm{TiO}_{2}$ will induce the decrease of light penetration via the shielding effect of the suspended particles, hence will drop the photo-degradation rate (Ahmed et al., 2011).

This finding corresponds to a study by Muneer and other researchers (2005), who reported on the photocatalysed reaction of propham, propachlor, and tebuthiuron in aqueous suspensions of $\mathrm{TiO}_{2}$. They suggested that optimum catalyst concentration has to be found in order to avoid excess catalyst and ensure total absorption of efficient photons. Other than that, Saquib et al. (2008) examined the destruction of acid blue under UV light irradiation in the range of 0.5 to $4.0 \mathrm{~g} / \mathrm{L} \mathrm{TiO}_{2}$ concentration and detected that the degradation rate reduces beyond 2.0 
$\mathrm{g} / \mathrm{L}$, due to the saturation of $\mathrm{TiO}_{2}$ particles, which inhibits the photon absorption on the catalyst surface. In the present study, an apparent plateau limit of $1.5 \mathrm{~g} / \mathrm{L}$ of $\mathrm{TiO}_{2}$ concentration for the photocatalytic degradation of the pollutants, led to the selection of $1.0 \mathrm{~g} / \mathrm{L}$ to $2.0 \mathrm{~g} / \mathrm{L} \mathrm{TiO}_{2}$ concentration as the suitable range for the batch experimental study

\subsubsection{Effect of $\mathrm{pH}$}

The interpretation of $\mathrm{pH}$ affecting the photo-degradation process is a difficult task since it is related to the ionization states of the $\mathrm{TiO}_{2}$ surface and the substrate, as well as the rate of formation of radicals in the reaction mixture. Variation of $\mathrm{pH}$ changes the surface charge of $\mathrm{TiO}_{2}$ and also shifts the potentials of photocatalytic reactions. Literature reveals that $\mathrm{TiO}_{2}$ has a point of zero charge (PZC) at pH 6.25, which means $\mathrm{TiO}_{2}$ surface remains positively-charged at $\mathrm{pH}$ $<6.25$ and negatively-charged at pH > 6.25 (Li et al., 2005; Muneer et al., 2005; Wang et al., 2009). At PZC, the interaction between the photo-catalyst particles and water contaminants is minimal due to the absence of any electrostatic force (Zamora, 2013). In order to increase the degradation rate of the pollutants, the attractive forces between the catalyst and the pollutants must occur.

Figure 2 demonstrates the effect of $\mathrm{pH}$ towards the photocatalytic degradation of NAP, FLT, PYR, LIN, and DDT. In this study, $\mathrm{pH}$ range was varied from 3 to 11 . The $\mathrm{pH}$ level which is below pH 3 is not preferable to be used because too acidic condition can be harmful when applied on site. While at a $\mathrm{pH}$ level above 11, or too alkaline condition, literature study had proven that the photo-degradation rate will decrease (Zhang et al., 2008). From the figure, it can be seen that FLT, PYR, and LIN exhibit the same pattern of removal degradation, with $\mathrm{pH} 7$ contributed the highest removal efficiencies. On the other hand, DDT removal was most favourable at $\mathrm{pH}$ 9, while NAP showed $100 \%$ removal at all $\mathrm{pH}$ medium without any slight difference in the degradation trend. The complete removal of NAP shows that heterogeneous photocatalysis process is able to eliminate NAP without any significant effect from $\mathrm{pH}$ variation.

According to Ahmed et al. (2011), characteristics of organic pollutants differ greatly in terms of solubility in water, hydrophobicity, speciation behaviour, and thus, their ionizable functional group. While some compounds exhibit a wide variation in the speciation charge, other compounds are uncharged at common $\mathrm{pH}$ conditions typical of natural water or wastewater. In addition, while positive ionnegative ion reactions have been studied for simple systems, no measurements exist for $\mathrm{PAH}$ ions (Bierbaum et al., 2011). The reason of why neutral or slightly alkaline $\mathrm{pH}$ triggered high removals of FLT and PYR was because the electrostatic attractive forces that exist between the cationic PAHs and negatively-charged $\mathrm{TiO}_{2}$. In particular, the influence of initial $\mathrm{pH}$ on the photo-catalytic process is more complex and the observed effect is generally dependent on the type of pollutant and the point of zero charge (PZC) of the photo-catalyst used in the oxidation process (Aljuboury et al., 2016).

Similar observation was reported by (Silva et al. 2007), who investigated the phenol degradation from photocatalytic treatment of simulated and actual olive mill wastewater, and determined the most favourable $\mathrm{pH}$ appears at a $\mathrm{pH}$ value slightly higher than the $\mathrm{PZC}$ of $\mathrm{TiO}_{2}$. Akpan and Hameed (2009) reported that the adsorption of the pollutant is known to be maximum near the PZC of the catalyst, because at low $\mathrm{pH}$, the positive holes are the major oxidation species, while at neutral or high $\mathrm{pH}$ levels, hydroxyl radicals are considered as predominant species. In the mechanism of photocatalysis, it is a fundamental knowledge to know the process that triggers the degradation of the contaminant molecules is the production of hydroxyl radicals.

In the present study, it can be seen that DDT was destructed efficiently at alkaline medium ( $\mathrm{pH} 9$ ), which displayed different trend from other pollutants. This might be attributed to the rapid generation of $\bullet \mathrm{OH}$ from the oxidation of $\mathrm{OH}^{-}$and positive holes on the $\mathrm{TiO}_{2}$ surface, thus the efficiency of the process is logically enhanced (Konstantinou and Albanis, 2004). This case is in agreement with Jang et al., (2005) findings, who discovered the photodegradation rate of DDT on the $\mathrm{TiO}_{2}$ film was higher at $\mathrm{pH}$ 10.4 than those at $\mathrm{pH} 4.6$ and $\mathrm{pH}$ 7.3.

On the contrary, low degradation rates of all compounds at low $\mathrm{pH}$ values can be explained by the agglomeration of $\mathrm{TiO}_{2}$, which tend to occur under acidic condition. Consequently the area available for adsorption of the pollutant and the photon is reduced (Bibak and Aliabadi, 2014). In addition, organic acids would strongly foul the $\mathrm{TiO}_{2}$ surface especially in acidic conditions, thus significantly reducing the photocatalytic activity (Katz et al., 2015). However, in some cases, degradation is more efficient under acidic conditions. In the photocatalytic degradation of Bromocresol purple dye, a six-fold increase in adsorption efficacy was observed after the solution was

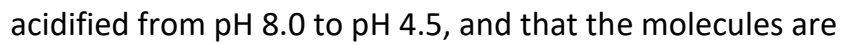
positively-charged. With that, such observation could not be explained (Baran et al., 2008).

In conclusion, $\mathrm{pH} 7$ was opted as the most favourable $\mathrm{pH}$ for destructing all the pollutants, although the best $\mathrm{pH}$ for DDT inactivation appears to be 9, but to consider the highest removals in the majority of compounds involved in this study. Moreover, photocatalytic treatment at neutral $\mathrm{pH}$ level is nearer to the initial $\mathrm{pH}$ of the synthetic solution and also the $\mathrm{pH}$ of actual rainwater itself, that are within 4.0 to 6.0 and 6.0 to 7.5 , respectively. Hence, it is advantageous for the treatment process because not much of $\mathrm{NaOH}$ is needed for the $\mathrm{pH}$ adjustment, and at once, the actual characteristic of the sample is also not going to differ much. Therefore, when the reasonable degradation at the neutral $\mathrm{pH}$ was considered, the suitable range used for the next batch study of the heterogeneous photocatalysis process was selected at $\mathrm{pH} 5$ to 9 . 


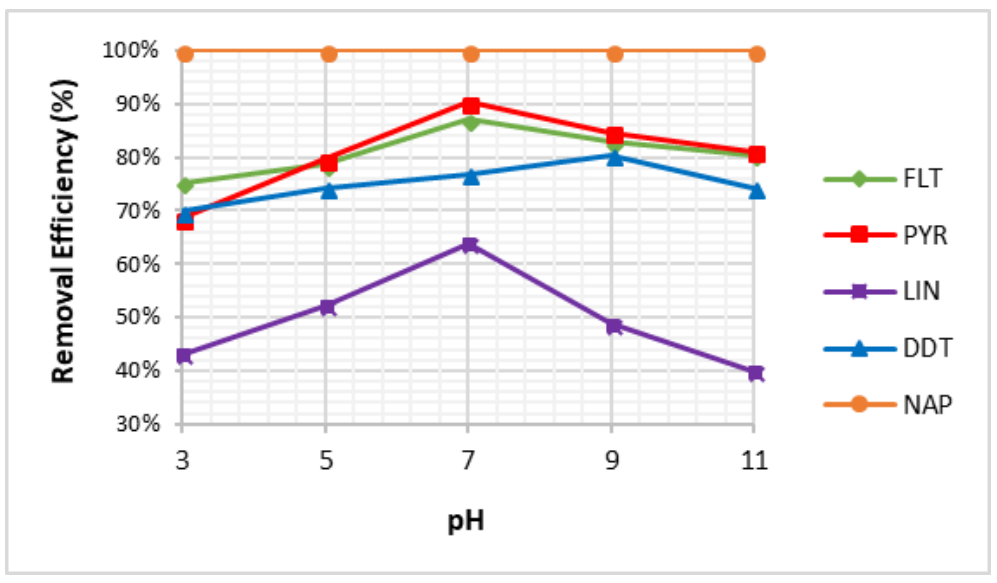

Figure 2. Effect of $\mathrm{pH}$ towards the photocatalytic degradation of NAP, FLT, PYR, LIN, and DDT

\subsubsection{Effect of Initial Concentration}

Figure 3 displays the effect of initial concentration towards the photocatalytic degradation of NAP, FLT, PYR, LIN, and DDT. From the graph, it can be seen that $100 \mu \mathrm{g} / \mathrm{L}$ and 125 $\mu \mathrm{g} / \mathrm{L}$ of initial concentrations for FLT, PYR, LIN, and DDT yield highest removal efficiencies, which are also quite near to each other. The results obtained for NAP which achieved $100 \%$ of removal percentage indicated that this substrate concentration factor did not influence the photocatalytic degradation process of NAP itself.

The degradation rate depends largely on the capacity of the molecules to adsorb on the catalyst surface or also called as mass transfer rate. Enhanced mass transfer can be achieved by using minor substrate particles, thereby altering the surface area and resulting in a higher dissolution rate (Uyguner-Demirel and Bekbolet, 2011). High amount of pollutant concentration can reduce the light penetration into the solution, thus decreases the oxidation rate. This also contributes to the competitiveness of active sites on the $\mathrm{TiO}_{2}$ surface. More pollutants' molecules adsorbed on the surface of $\mathrm{TiO}_{2}$ photocatalyst will make fewer active sites available for the hydroxyl radicals' adsorption. Hence, large amounts of initial pollutants would have an inhibitory influence on the reaction between pollutants' molecules and hydroxyl radicals due to the lack of any direct contact between them (Bibak and Aliabadi, 2014).

The results obtained in this work are in agreement to Ananpattarachai and Kajitvichyanukul's (2015) findings, which concluded that at higher initial amount of DDT, the active sites of the $\mathrm{TiO}_{2}$ surface were covered with DDT molecules and thus, decreasing the path length of photons entering the solution. Lam et al. (2010) indicated similar results, and photons do not reach the surface of photocatalyst to activate it to generate hydroxyl radicals. Due to that, initial concentration range of $100 \mu \mathrm{g} / \mathrm{L}$ to 150 $\mu \mathrm{g} / \mathrm{L}$ was chosen in order to determine the optimum value of the photocatalytic treatment process.

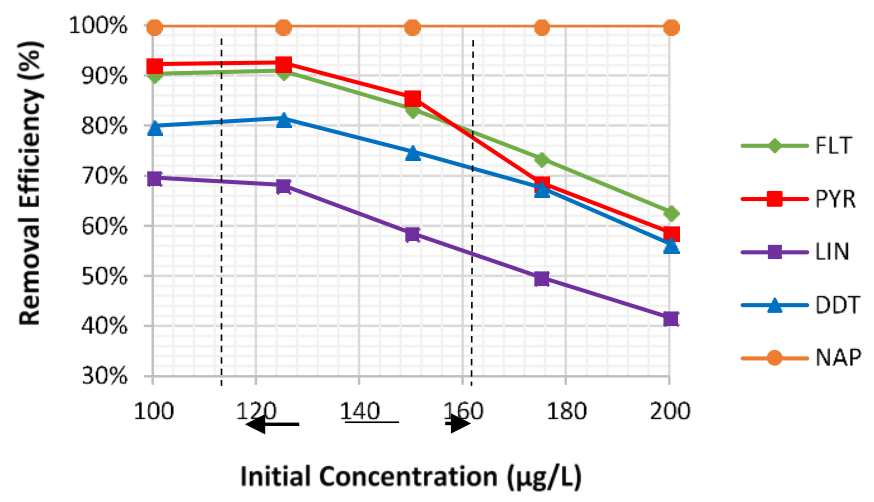

Figure 3. Effect of initial concentration towards the photocatalytic degradation of NAP, FLT, PYR, LIN, and DDT

In overall results, it can be seen that lindane has been the lowest micro-organic pollutant to be efficiently degraded in this photocatalytic process. Lindane is less prone to oxidation due to its non-aromatic and saturated structure and the absence of a double bond (Senthilnathan and Philip, 2010). Single bond in its molecular structure explains that it is more stable compared to NAP, FLT, PYR, and DDT which consist of double bonds in their molecular structure, because it has a lower level of reactivity, meaning to be less vulnerable in losing electrons to atoms that want to steal electrons.

On the other hand, it was suggested that aromatic compounds such as NAP, FLT, and PYR were the major species absorbing UV photons because of their abundance and UV sensitivity. In addition, the aromatic species (FLT and PYR) also have a similar manner during the 
photocatalytic process: photo-adsorption on the active surface sites and similar degradation trends (Liu et al. 2016). Haritash and Kaushik, (2009) stated that with an increase in molecular weight, their solubility in water decreases, melting and boiling point increase and vapour pressure decreases.

Although fluoranthene and pyrene have the same molecular weight that are $202.25 \mathrm{~g} / \mathrm{mol}$, fluoranthene is considered as LMW PAH for having 3 aromatic rings while pyrene is considered as HMW PAH for having 4 aromatic rings in their molecular structures. Therefore, pyrene is more hydrophobic and has more affinity for $\mathrm{TiO}_{2}$, which then generated faster photo-degradation process to occur (Rubio-Clemente et al., 2014). On top of that, for NAP case, which has very high removal rates despite of various working conditions examined in this treatment process, shows an unsuitable result to be investigated. Generally, among all PAH compounds, NAP which has the least number of aromatic benzene rings in its molecular structure, is the most soluble and volatile PAH, hence, easily evaporated at normal temperatures (RubioClemente et al., 2014).

A study was done by Luo et al. (2015b) to assess the correlation between the photocatalytic degradability of $\mathrm{PAHs}$ over $\mathrm{Pt} / \mathrm{TiO}_{2}-\mathrm{SiO}_{2}$ in water and their quantitative molecular structure. In their work, they predicted the photocatalytic degradability through a quantitative structure activity relationships (QSAR) modelling, which measures the necessary energy to excite an electron from the highest to the lowest occupied molecular orbitals. As the result, they evaluated that NAP has non-photocatalytic degradability because the energy required upon its molecule excitability is greater compared to other compounds, since it has the lowest molecular weight in PAH group.

After these reasonable explanations were measured, it was declared that NAP was excluded from the batch experimental study of the heterogeneous photocatalytic treatment process. This was due to the lacking in behaviour and performance shown by the compound in the mixture solution throughout previous experimental studies, which evaporates very easily in the aqueous environment. Hence, more detailed step of preservation is required, in order to maintain the original characteristic and properties of the compound at its best. This, in turn, makes it hard to investigate the factors that control the degradation behaviour of NAP in the photocatalytic system.

\subsection{The statistical design of the experiments.}

Every experimental run conducted in batch study was designed and analysed by RSM in Design Expert Software version 6.0.6 (STAT-EASE Inc., Minneapolis, US. In the present study, RSM was used as a tool to design the experimental conditions, evaluate the significance and relationship between the responses: FLT, PYR, LIN, and DDT; and independent variables: $\mathrm{pH}, \mathrm{TiO}_{2}$ concentration, and initial concentration; through analysis of variance (ANOVA), as well as to optimize the treatment conditions of each independent variable.

Table 2. Design matrix of three independent variables and the obtained output responses

\begin{tabular}{|c|c|c|c|c|c|c|c|c|c|c|c|}
\hline \multirow{2}{*}{ No. } & \multirow{2}{*}{$A: p H$} & \multirow{2}{*}{$\mathrm{B}: \mathrm{TiO}_{2}(\mathrm{~g} / \mathrm{L})$} & \multirow{2}{*}{ C: $C_{0}(\mu \mathrm{g} / \mathrm{L})$} & \multicolumn{4}{|c|}{ Response, $\mathrm{Y}_{\exp }(\%)$} & \multicolumn{4}{|c|}{ Response, $Y_{\text {pre }}(\%)$} \\
\hline & & & & FLT & PYR & LIN & DDT & FLT & PYR & LIN & DDT \\
\hline 1 & -1 & -1 & -1 & 80 & 81 & 42 & 76 & 80 & 81 & 45 & 76 \\
\hline 2 & 1 & -1 & -1 & 82 & 82 & 42 & 83 & 82 & 82 & 42 & 84 \\
\hline 3 & -1 & 1 & -1 & 83 & 84 & 52 & 75 & 83 & 84 & 50 & 75 \\
\hline 4 & 1 & 1 & -1 & 84 & 85 & 42 & 87 & 84 & 85 & 45 & 86 \\
\hline 5 & -1 & -1 & 1 & 78 & 80 & 40 & 70 & 78 & 80 & 37 & 70 \\
\hline 6 & 1 & -1 & 1 & 80 & 81 & 36 & 76 & 80 & 81 & 37 & 75 \\
\hline 7 & -1 & 1 & 1 & 80 & 82 & 40 & 76 & 80 & 82 & 40 & 75 \\
\hline 8 & 1 & 1 & 1 & 80 & 82 & 42 & 83 & 80 & 82 & 38 & 83 \\
\hline 9 & -1 & 0 & 0 & 88 & 90 & 57 & 79 & 88 & 90 & 60 & 80 \\
\hline 10 & 1 & 0 & 0 & 90 & 91 & 57 & 87 & 89 & 91 & 57 & 88 \\
\hline 11 & 0 & -1 & 0 & 82 & 84 & 52 & 75 & 81 & 83 & 51 & 75 \\
\hline 12 & 0 & 1 & 0 & 83 & 85 & 50 & 75 & 83 & 85 & 54 & 78 \\
\hline 13 & 0 & 0 & -1 & 92 & 92 & 70 & 80 & 92 & 91 & 67 & 80 \\
\hline 14 & 0 & 0 & 1 & 90 & 89 & 53 & 73 & 89 & 89 & 59 & 75 \\
\hline 15 & 0 & 0 & 0 & 91 & 92 & 67 & 80 & 90 & 91 & 66 & 80 \\
\hline 16 & 0 & 0 & 0 & 90 & 92 & 68 & 81 & 90 & 91 & 66 & 80 \\
\hline 17 & 0 & 0 & 0 & 89 & 91 & 66 & 81 & 90 & 91 & 66 & 80 \\
\hline 18 & 0 & 0 & 0 & 88 & 91 & 67 & 81 & 90 & 91 & 66 & 80 \\
\hline 19 & 0 & 0 & 0 & 91 & 90 & 68 & 80 & 90 & 91 & 66 & 80 \\
\hline 20 & 0 & 0 & 0 & 88 & 90 & 68 & 81 & 90 & 91 & 66 & 80 \\
\hline
\end{tabular}

Central composite design (CCD), a popular second order experimental design, provides reasonable amount of information for testing the goodness of fit and does not require large number of design points (Sharma et al., 2009).
Generally, the full factorial CCD consists of $2^{k}$ factorial points, augmented by a centre point and two axial points on the axis of each design variables at a distance of $\alpha$ from the centre point (Jo et al., 2008). In this study, the 
independent variables varied over three levels, namely -1 , 0 , and +1 , and the range was determined from the preliminary studies. Figure 2 presents the design matrix of three independent variables and the obtained output responses. The experimental output responses (Yexp) were calculated based on the efficiency test using Equation (1), whereas the predicted output responses (Ypre) were calculated in the software. There was a total number of 20 experimental runs needed to be carried out. Six replications from run 15 to run 20 were included in order to evaluate the pure error (Sharma et al., 2009).

By referring to the table, a majority of the actual results obtained was similar to the predicted values by model. The highest percentage of removal obtained from the experimental run (actual) for FLT, PYR, LIN, and DDT were $91 \%, 92 \%, 70 \%$, and $87 \%$, respectively. Reduction in $\mathrm{PAH}$ (FLT and PYR) compounds was considerably high, which was achieved using $1.5 \mathrm{~g} / \mathrm{L} \mathrm{TiO}_{2}$ concentration and $125 \mu \mathrm{g} / \mathrm{L}$ at $\mathrm{pH} 7$ (, 70\% of LIN was removed after being irradiated for 30 minutes, at treatment conditions as the following: $\mathrm{pH}$ : 7; $\mathrm{TiO}_{2}$ concentration: $1.5 \mathrm{~g} / \mathrm{L}$; and initial concentration: $100 \mu \mathrm{g} / \mathrm{L}$. The highest percentage removal of DDT (87\%) occurred at $\mathrm{pH} 9, \mathrm{TiO}_{2}$ concentration of $1.5 \mathrm{~g} / \mathrm{L}$, and 125 $\mu \mathrm{g} / \mathrm{L}$. Dbrowski et al., (2012) demonstrated the $38.5 \%$ and $60.3 \%$ removals of LIN and DDT at pH 6 were improved to $41.2 \%$ and $85.1 \%$, respectively, at $\mathrm{pH} 11$ after 60 minutes of irradiation in $200 \mathrm{mg} / \mathrm{L}$ aqueous suspension.

\subsubsection{Analysis of Variance (ANOVA)}

Based on the results from the CCD design, analyses were carried out to obtain the regression model. The responses and corresponding parameters were analysed using analysis of variance (ANOVA) to further estimate the significance of the variables and models involved in this study. According to the sequential model sum of squares, the models were selected based on the highest order polynomials where the additional terms were significant and the models were not aliased. For all four responses, quadratic models were selected as suggested by the software. The final generated empirical formula models of FLT, PYR, LIN, and DDT, which coded as $Y_{1}, Y_{2}, Y_{3}$, and $Y_{4}$, respectively, are represented by Equations (2) to (5). Equations from the first analysis for the four models were modified by eliminating the terms found to have limited influence to the respective models. The coefficient with one factor represents the effect of the particular factor, while the coefficients with two factors and those with second-order terms represent the interaction between the two factors and quadratic effect, respectively (Ahmad and Hameed, 2010).

A positive sign in front of the terms indicates a synergistic effect, whereas a negative sign indicates an antagonistic effect (Tan et al., 2008). A synergistic effect occurs when the sum of the effect is greater than each component individually, and antagonism occurs when the net effect of the chemical reaction is becoming zero or less than the effect that would be predicted from an individual component (Carolina et al., 2015).

$$
\begin{aligned}
& Y_{1}=89.88+0.70 A+0.80 B-1.30 C-1.45 A^{2}-7.95 B^{2}+0.55 C^{2} \\
& Y_{1}=89.88+0.70 A+0.80 B-1.30 C-1.45 A^{2}-7.95 B^{2}+0.55 C^{2} \\
& Y_{3}=66.29-1.20 A+1.40 B-3.70 C-7.73 A^{2}-13.73 B^{2}-3.23 C^{2} \\
& Y_{4}=79.93+4.00 A+1.60 B-2.30 C+4.18 A^{2}-3.82 B^{2}-2.32 C^{2}+1.25 B C
\end{aligned}
$$

In ANOVA, if the value of Prob $>F$ is less than 0.05, the model terms are considered as significant (Sahu et al., 2010). Meanwhile, if the values of Prob $>F$ is greater than 0.10 , it indicates that the model terms are not significant (Cicek et al., 2008).

Any statistical analysis needs validation to decide whether the numerical results quantifying the siginificance and relationships between variables obtained from regression analysis, are acceptable or not. The standard deviation obtained were $1.15,0.79,3.34$ and 1.67 for $Y 1, Y 2, Y 3$ and $\mathrm{Y} 4$ respectively. It is worthy to note that the smaller the standard deviation, the better is the model because it indicated that the data points tend to be closer to the mean. In other words, it gives predicted values that are closer to the actual values for the response.

The $R^{2}$ values was found high for $Y_{2}\left(R^{2}=0.9834\right)$, followed by $Y_{1}\left(R^{2}=0.9676\right), Y_{3}\left(R^{2}=0.9499\right)$ and $Y_{4}\left(R^{2}=0.9337\right)$. The $R^{2}$ coefficient gives the proportion of the total variation in the response predicted by the model (Ghafari et al., 2009). The closer the $R^{2}$ value is to 1 , the better the model predicts the response (Aghaie et al., 2009). A reasonable agreement of $R^{2}$ and adjusted $R^{2}$ is necessary, which evaluates the quality of the fit of polynomial model. It is known that $R^{2}$ increases in accordance to the number of additional terms to the model, whereas the adjusted $R^{2}$ does not. Thus, the adjusted $R^{2}$ is often smaller than $R^{2}$, which corresponds to the results obtained for all models according to the table.

Meanwhile, adequate precision is a measure of the range in predicted response relative to its associated error or, in simpler words, a signal noise ration (Zinatizadeh et al., 2007). The ratios obtained for models $Y_{1}, Y_{2}, Y_{3}$ and $Y_{4}$, were $16.41,19.76,11.64$ and 16.03, respectively, which are in agreement of desirable ratios of above 4 . Simultaneously, low values of the coefficient of variance (C.V.) were attained $\left(1.35,0.91\right.$ and 2.12 for $Y_{1}, Y_{2}, Y_{3}$ and $Y_{4}$, respectively) except for model $Y_{3}$ (6.20). Despite that, the $\mathrm{CV}$ value must be lesser than 10 , otherwise the proposed model cannot be considered reproducible (Mahmoodi and Sargolzaei, 2014). 
Table 3 presents the ANOVA of the quadratic models of $Y_{1}$, $Y_{2}, Y_{3}$, and $Y_{4}$. The $F$-values of $33.20,65.68,37.50$, and 17.21 for $Y_{1}, Y_{2}, Y_{3}$, and $Y_{4}$, respectively, and the values of Prob > $F$ less than 0.05 imply that all models were significant.

In case of $Y_{1}$, it can be seen from the table that only initial concentration (C) and the quadratic effect of $\mathrm{TiO}_{2}$ concentration $\left(\mathrm{B}^{2}\right)$ were significant terms to the model.

Table 3. ANOVA of the quadratic models for $Y_{1}, Y_{2}, Y_{3}$, and $Y_{4}$

\begin{tabular}{|c|c|c|c|}
\hline Source & F-value & Prob $>$ F & Comment \\
\hline Model $\left(\mathrm{Y}_{1}\right)$ & 33.20 & $<0.0001$ & significant \\
\hline$A$ & 3.68 & 0.0840 & \\
\hline$B$ & 4.81 & 0.0531 & \\
\hline $\mathrm{C}$ & 12.70 & 0.0051 & \\
\hline$A^{2}$ & 4.37 & 0.0630 & \\
\hline $\mathrm{B}^{2}$ & 130.76 & $<0.0001$ & \\
\hline$C^{2}$ & 0.61 & 0.4511 & \\
\hline Model $\left(Y_{2}\right)$ & 65.68 & $<0.0001$ & significant \\
\hline $\mathrm{A}$ & 2.57 & 0.1400 & \\
\hline$B$ & 16.06 & 0.0025 & \\
\hline $\mathrm{C}$ & 16.06 & 0.0025 & \\
\hline$A^{2}$ & 4.42 & 0.0619 & \\
\hline$B^{2}$ & 216.47 & $<0.0001$ & \\
\hline$C^{2}$ & 4.42 & 0.0619 & \\
\hline Model $\left(\mathrm{Y}_{3}\right)$ & 37.50 & $<0.0001$ & significant \\
\hline $\mathrm{A}$ & 1.29 & 0.2769 & \\
\hline B & 1.75 & 0.2083 & \\
\hline$C$ & 12.24 & 0.0039 & \\
\hline$A^{2}$ & 14.69 & 0.0021 & \\
\hline $\mathrm{B}^{2}$ & 46.35 & $<0.0001$ & \\
\hline$C^{2}$ & 2.56 & 0.1335 & \\
\hline Model $\left(Y_{4}\right)$ & 17.21 & $<0.0001$ & significant \\
\hline $\mathrm{A}$ & 57.13 & $<0.0001$ & \\
\hline$B$ & 9.14 & 0.0106 & \\
\hline $\mathrm{C}$ & 18.89 & 0.0010 & \\
\hline$A^{2}$ & 17.17 & 0.0014 & \\
\hline $\mathrm{B}^{2}$ & 14.31 & 0.0026 & \\
\hline$C^{2}$ & 5.28 & 0.0404 & \\
\hline $\mathrm{BC}$ & 4.46 & 0.0563 & \\
\hline
\end{tabular}

Whereas for $\mathrm{Y}_{2}, \mathrm{TiO}_{2}$ concentration (B) and initial concentration (C), as well as the quadratic effect of $\mathrm{TiO}_{2}$ concentration $\left(\mathrm{B}^{2}\right)$ were significant terms to the model. On the other hand, the significant terms to model $Y_{3}$ obtained from the analysis were the initial concentration (C), as well as the quadratic effects of $\mathrm{pH}\left(\mathrm{A}^{2}\right)$ and $\mathrm{TiO}_{2}$ concentration $\left(B^{2}\right)$. Meanwhile, for $Y_{4}$, all model terms were significant to the model except for interaction term (BC).
From the statistical results obtained, the models were all adequate to predict the removal percentage of FLT, PYR, LIN, and DDT. Nevertheless, it is vital to ensure that selected models are providing an adequate approximation to the real system. By applying the diagnostic plots such as the predicted versus actual plot, the model adequacy can be concluded. Figure 6 displays the predicted versus actual plot for FLT, PYR, LIN, and DDT models.

Generally, the line passed through the middle of the plot over the whole range of the data for FLT, PYR, LIN, and DDT removals. This indicates that the predicted values of the responses obtained from the software and the actual experimental data were in good agreement. Any points above or below the straight line signified over or under predicting. However, it can be judged that most of the points were relatively close to the straight line for FLT, PYR, LIN, and DDT removals, respectively. These plotted graphs were also consistent with results from the statistical analysis (high $\mathrm{R}^{2}$ values).

In order to study the interactive effect between all three variables and four responses, 3D response plots were drawn for FLT, PYR, LIN and DDT models, as shown Figure 4. In these figures, two variables were varied while the other one was kept constant. The selectivity of the constant variable was chosen based on the level of sensitivity of the variables toward the responses (Adlan et al., 2011). Generally, quadratic models for all the parameters were visualized by parabolic shape for all responses.

As depicted in Figure 4(a), the removal of FLT reached maximum of approximately $88 \%$, with an optimum condition at $\mathrm{pH} 7$ and a $\mathrm{TiO}_{2}$ concentration of $1.5 \mathrm{~g} / \mathrm{L}$. Increasing dosages of $\mathrm{TiO}_{2}$ concentration at $\mathrm{pH} 7$ only lowered down the percentage removal of FLT. Since the 
initial concentration showed an optimum performance at its favourable condition, it was kept constant at $125 \mu \mathrm{g} / \mathrm{L}$. This agreed with the perturbation plot which showed $\mathrm{TiO}_{2}$ concentration as the most influential factor, followed by $\mathrm{pH}$, and initial concentration as the least significant factor affecting the treatment process. Likewise, response surface plot in Figure 8 (b) indicate optimum points to be also at about $\mathrm{pH} 7$ and $1.5 \mathrm{~g} / \mathrm{L} \mathrm{TiO}_{2}$ concentration, with $90 \%$ removal of PYR. In a nutshell, FLT and PYR have revealed a similar behaviour towards all variables, with removals that were nearly equal to each other.

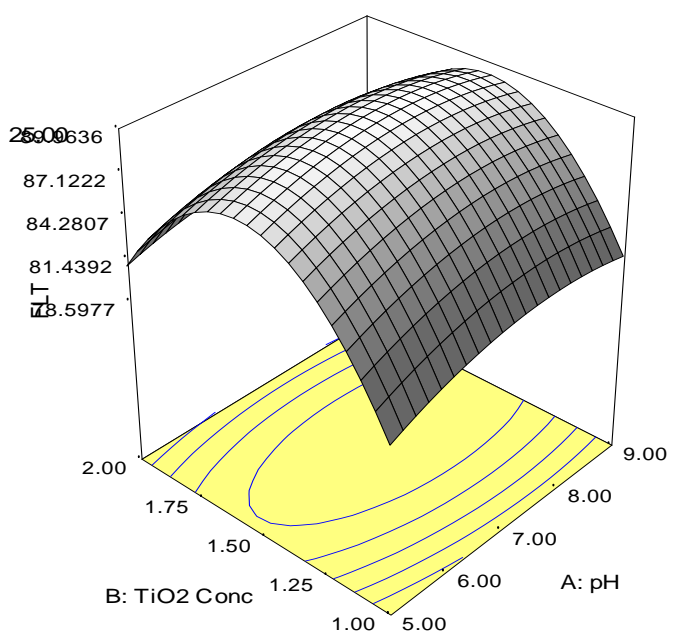

(a)

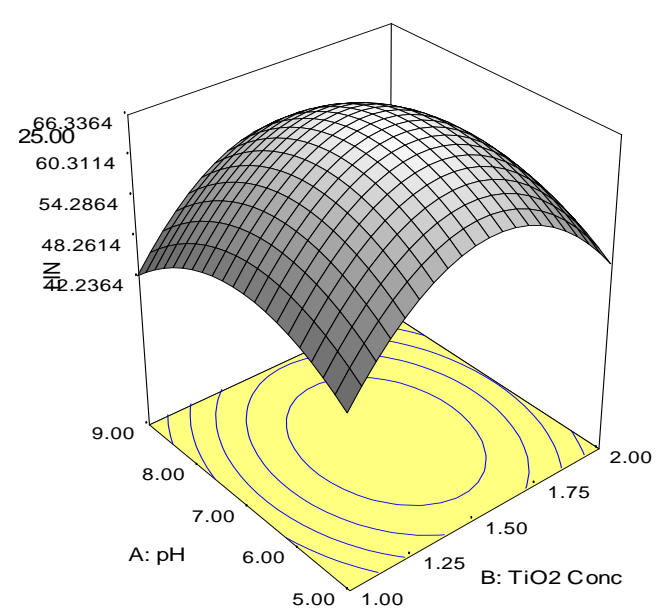

(c)
Based on Figure 4(c), it was suggested that $60 \%$ of LIN removal was achieved with a working condition of $\mathrm{pH} 7$ and a $\mathrm{TiO}_{2}$ concentration of $1.5 \mathrm{~g} / \mathrm{L}$. Removal efficiencies were found to reduce when moving away from these points, meaning that either increase or decrease in any of the tested variables results in decline of LIN as the model response. In Figure $4(\mathrm{~d}), \mathrm{TiO}_{2}$ concentration and initial pollutant concentration were varied while $\mathrm{pH}$ was kept constant at 7. The highest removal was obtained at lower DDT concentration of $100 \mu \mathrm{g} / \mathrm{L}$ to $125 \mu \mathrm{g} / \mathrm{L}$, also with a favourable point of $\mathrm{TiO}_{2}$ dosage. In this condition, DDT was approximately removed by $78 \%$.

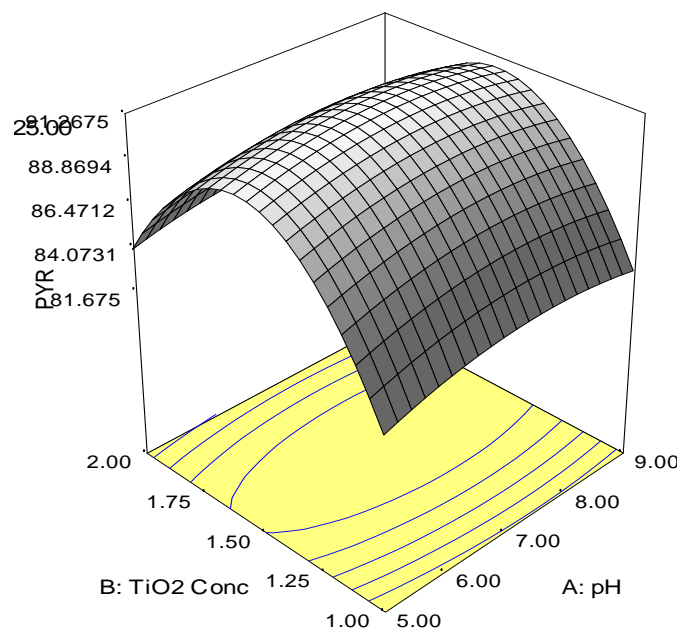

(b)

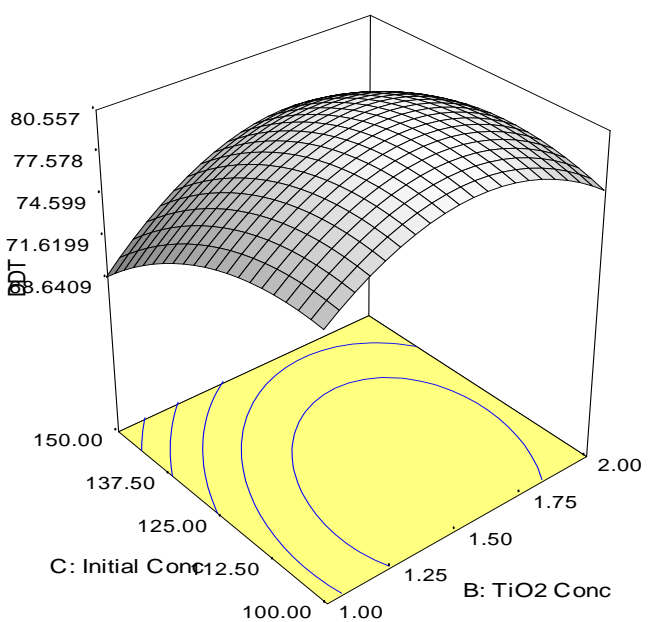

(d)

Figure 4. 3D surface plot for (a) FLT (b) PYR (c) LIN (d) DDT

\subsubsection{Optimization}

Graphical optimization was used to determine the optimal treatment conditions for the maximum removal efficiencies of FLT, PYR, LIN, and DDT from the synthetic rainwater when irradiated for 30 minutes of treatment time. The contour line for response surfaces were superimposed in an overlay plot. The shaded portion of the overlay plot indicates the optimum region identified by considering the highest degradation removals of the responses.

As plotted in the graph, $\mathrm{pH}$ and $\mathrm{TiO}_{2}$ concentration were varied since these two independent variables were significantly influenced the responses. On the other hand, initial concentration of the two responses was kept constant at $125 \mu \mathrm{g} / \mathrm{L}$. Based on the optimum region shown, the optimum condition of this photocatalytic treatment 
process occurred at $\mathrm{pH}(7), \mathrm{TiO}_{2}$ concentration $(1.54 \mathrm{~g} / \mathrm{L})$ and initial concentration $(125 \mu \mathrm{g} / \mathrm{L})$, by eliminating as high as $90 \%$ FLT, $91 \%$ PYR, $66 \%$ LIN, and $80 \%$ DDT concentrations in the rainwater sample. These optimum removal efficiencies, as predicted by the models, were calculated using Equations (2), (3), (4), and (5) respectively, and presented in Table 4.

Table 4. Model validation for optimization procedure

\begin{tabular}{lcccc}
\hline & \multicolumn{3}{c}{ Responses } \\
\cline { 2 - 5 } & FLT & PYR & LIN & DDT \\
\hline Experimental value & $88 \%$ & $90 \%$ & $66 \%$ & $79 \%$ \\
\hline Model response & $90 \%$ & $91 \%$ & $66 \%$ & $80 \%$ \\
\hline Error & 2 & 1 & 0 & 1 \\
\hline Standard deviation & 1.18 & 0.71 & 0.24 & 0.71 \\
\hline
\end{tabular}

To confirm the model adequacy, the model was validated by carrying out experimental run using the same treatment conditions of $\mathrm{pH}(7), \mathrm{TiO}_{2}$ concentration $(1.54 \mathrm{~g} / \mathrm{L})$, and initial concentration $(125 \mu \mathrm{g} / \mathrm{L})$. Three replicative experiments were carried out in the reactor which yielded average maximum degradation of $88 \%$ for fluoranthene, $90 \%$ for pyrene, $66 \%$ for lindane, and $79 \%$ for DDT. Good agreement between the predictive and experimental results verified the validity of obtained optimal points.

\subsection{Kinetic Mechanism of Photocatalytic Degradation}

Ultimately, a kinetic model is needed for predicting the performance in different water conditions (Liga et al., 2013). Photocatalytic disinfection of micro-pollutants is largely determined by adsorption of the micro-pollutants on the photocatalyst surface and the rate of reactive oxidant species (ROS) production (Foster et al., 2011). It has been reported that the initial rate of disappearance of the pollutants fit a Langmuir-Hinshelwood (L-H) kinetic scheme (Malato et al., 2009). Therefore, kinetic phase of the photocatalytic degradation process of FLT, PYR, LIN, and DDT was completed according to $\mathrm{L}-\mathrm{H}$ model in this study, prior to the evaluation of the removal efficiencies obtained throughout this process. The kinetic characteristics such as the reaction order, values of $k_{a p p}, k$, and $\mathrm{K}$ were determined as for the kinetic evaluation. Four experimental run was performed which involved four initial concentrations, comprised of $100 \mu \mathrm{g} / \mathrm{L}, 115 \mu \mathrm{g} / \mathrm{L}, 130 \mu \mathrm{g} / \mathrm{L}$, and $150 \mu \mathrm{g} / \mathrm{L}$.

\subsubsection{Determination of Kinetic Order and Apparent Rate Constant}

In non-linear method, a graph of residual concentration versus time was plotted for FLT, PYR, LIN, and DDT. While varying the initial concentration, other factors were kept constant at each of their optimum values, which were $\mathrm{pH}$ (7) and $\mathrm{TiO}_{2}$ concentration $(1.5 \mathrm{~g} / \mathrm{L})$, as well as treatment period that was fixed to 30 minutes of exposure time. From the graphs, it was observed that all four pollutants exhibited an exponential trend in their respective plots, thus suggesting that the degradation of FLT, PYR, LIN, and DDT were following pseudo first order rate or reaction.

Hence, for linear method, kinetic plots were further explored based on the first order results obtained previously in non-linear method. Following the pseudo first order rate of reaction, Equation (6) was used to express the kinetic mechanism of the process, in which $\mathrm{k}_{\mathrm{app}}$ values were determined from the slope of In $C_{0} / C_{T}$ versus $t$ graph. Figure 5 illustrates the plot of $\operatorname{In} \mathrm{C}_{0} / \mathrm{C}_{\mathrm{T}}$ against treatment period under different initial concentrations of FLT, PYR, LIN, and DDT.

$$
\ln \left(\frac{C_{0}}{C_{t}}\right)=k_{a p p} \cdot t
$$

The linear plots observed in Figure 5 with high $R^{2}$ values obtained confirmed that the photocatalytic degradation process of FLT, PYR, LIN, and DDT in this study was in accordance to pseudo first order kinetic reaction. Besides that, it can be concluded in overall that the increment of initial concentration can only lower down the reaction rate of the photocatalytic degradation process, concerning the four pollutants. For instance, the $k_{a p p}$ values obtained for FLT were $0.2084 \mathrm{~min}^{-1}, 0.1759 \mathrm{~min}^{-1}, 0.1673 \mathrm{~min}^{-1}$, and $0.1189 \mathrm{~min}^{-1}$ for initial concentrations of $100 \mu \mathrm{g} / \mathrm{L}, 115$ $\mu \mathrm{g} / \mathrm{L}, 130 \mu \mathrm{g} / \mathrm{L}$, and $150 \mu \mathrm{g} / \mathrm{L}$, respectively. PYR, LIN, and DDT also revealed the same pattern of degradation in respect to the initial concentrations, like FLT.

According to the results obtained, the lowest initial concentration $(100 \mu \mathrm{g} / \mathrm{L})$ contributed to highest $\mathrm{k}_{\mathrm{app}}$ values of FLT, PYR, LIN, and DDT, which were $0.2084 \mathrm{~min}^{-1}, 0.2132$ $\mathrm{min}^{-1}, 0.1107 \mathrm{~min}^{-1}$, and $0.1598 \mathrm{~min}^{-1}$, respectively. On the other hand, the highest initial concentration $(150 \mu \mathrm{g} / \mathrm{L})$ contributed to lowest $k_{\text {app }}$ values of FLT, PYR, LIN, and DDT, which were $0.1189 \mathrm{~min}^{-1}, 0.132 \mathrm{~min}^{-1}, 0.0750 \mathrm{~min}^{-1}$, and $0.0981 \mathrm{~min}^{-1}$, respectively. As more substrate molecules were being introduced, this could promote the pollutant molecules to adsorb light and photons could not reach the $\mathrm{TiO}_{2}$ surface to generate hydroxyl radicals, and hence, photo-degradation efficiency decreases (Djokic et al., 2012).

At low initial pollutant concentrations, the amount of pollutant molecules is all adsorbed on the reactive sites of $\mathrm{TiO}_{2}$, so the reaction rate increases dramatically, and this reaction process is called a mass-transfer controlled step or a rate controlled step. On the other hand, at high initial concentrations of pollutants, when the amount of the pollutant molecules adsorbed on the $\mathrm{TiO}_{2}$ catalyst is saturated, the reaction rate changed very little, and this process is called a photon-transfer controlled step. In short, the kinetics of the photocatalytic degradation of pollutants are mostly governed by the mass-transfer effect at low 
concentrations of reactants and adsorption characteristics of catalyst. This is in agreement with Geng and other researchers (2008), who investigated the degradation kinetics of benzene and found out that the reaction rate of benzene degradation decreased in the concentration range

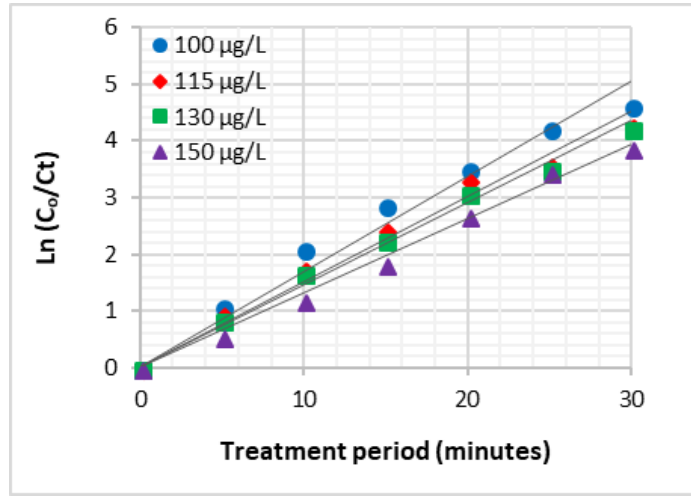

(a)

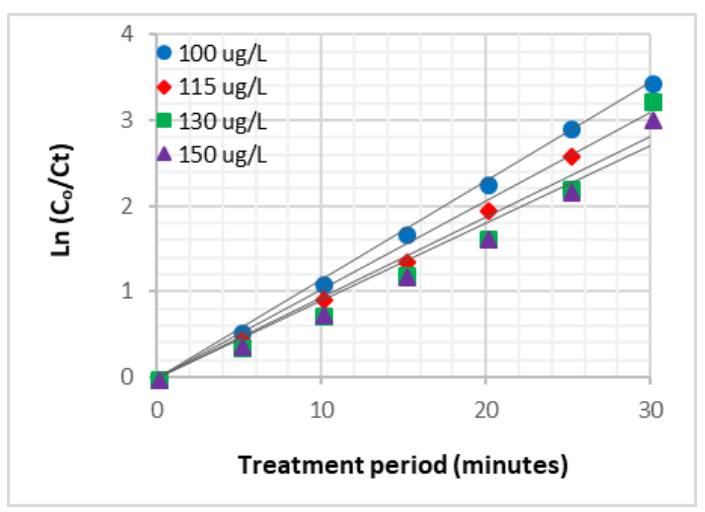

(c) from 20.78 to $52.12 \mathrm{mg} / \mathrm{L}$. Besides that, the stated $\mathrm{k}_{\mathrm{app}}$ values indicate that the most efficient pollutant being degraded was PYR, followed by FLT, DDT, and LIN.

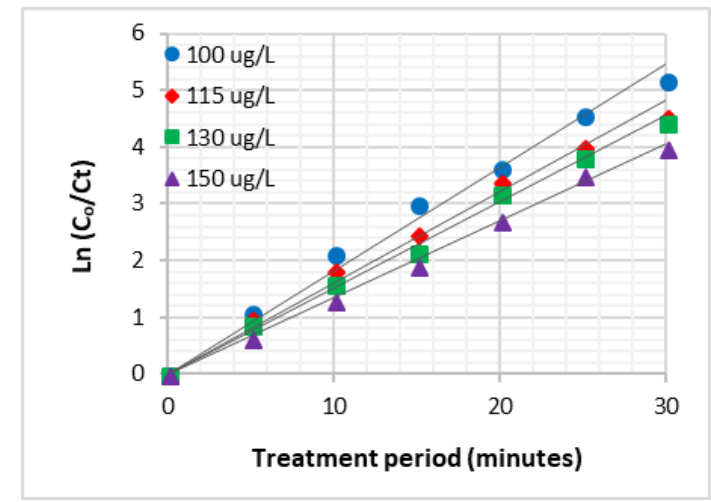

(b)

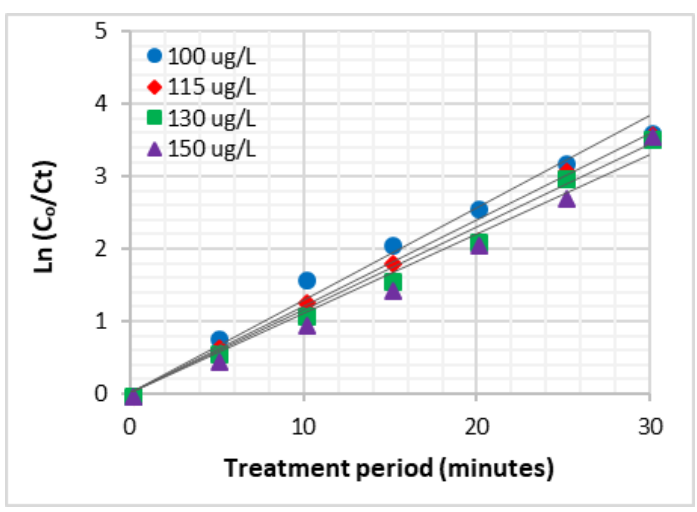

(d)

Figure 5. Plot of In $\mathrm{C}_{0} / \mathrm{C}_{\mathrm{T}}$ against treatment period under different initial concentrations of (a) FLT (b) PYR (c) LIN (d) DDT; $\mathrm{pH}=7, \mathrm{TiO}_{2}$ concentration $=1.5 \mathrm{~g} / \mathrm{L}$, treatment period $=30$ minutes

\subsubsection{Determination of Surface Reaction Rate Constant ( $k$ ) and Adsorption Equilibrium Constant $(K)$}

The L-H model was established to describe the dependence of the observed reaction rate on the initial solute concentrations (Konstantinou and Albanis, 2004). The initial concentrations of the pollutant has a fundamental effect on the degradation rate, in which the kinetic rate constant decreases with the increase of the initial pollutant concentration (Khezrianjoo and Revanasiddappa, 2012). The $\mathrm{L}-\mathrm{H}$ rate expression is given by Equation (7). The applicability of this L-H equation for the photocatalytic degradation was confirmed by the linear plot obtained by plotting the reciprocal of the rate constant $\left(1 / k_{a p p}\right)$ against the initial concentration of pollutants $\left(C_{0}\right)$, as shown in Figure 6.

$$
\frac{1}{\mathrm{k}_{\mathrm{app}}}=\frac{1}{\mathrm{k}} \mathrm{C}_{0}+\frac{1}{\mathrm{k}, \mathrm{K}}
$$

Linear plots obtained for FLT, PYR, LIN, and DDT with good correlation coefficient $\left(R^{2}\right)$ values of $0.9095,0.9938$, 0.8418 , and 0.9836 , respectively, confirming that this photocatalytic oxidation process fitted well with L-H model used. The values of surface reaction rate $(k)$ and $\mathrm{L}-\mathrm{H}$ adsorption equilibrium $(\mathrm{K})$ constants were calculated from the slope and the intercept of the straight line. PYR attained the highest $\mathrm{k}$ constant, which was $0.0176 \mathrm{mg} / \mathrm{L}$. min, followed by FLT, DDT, and LIN, which attained 0.0145 $\mathrm{mg} / \mathrm{L} \mathrm{min}, 0.0128 \mathrm{mg} / \mathrm{L} \mathrm{min}$ and $0.0111 \mathrm{mg} / \mathrm{L} \mathrm{min}$, respectively. Meanwhile, LIN achieved the highest $K$ constant, which was $198.28 \mathrm{~L} / \mathrm{mg}$, followed by DDT, PYR, and FLT, which achieved $56.52 \mathrm{~L} / \mathrm{mg}, 52.61 \mathrm{~L} / \mathrm{mg}$, and 29.78 $\mathrm{L} / \mathrm{mg}$, respectively. 


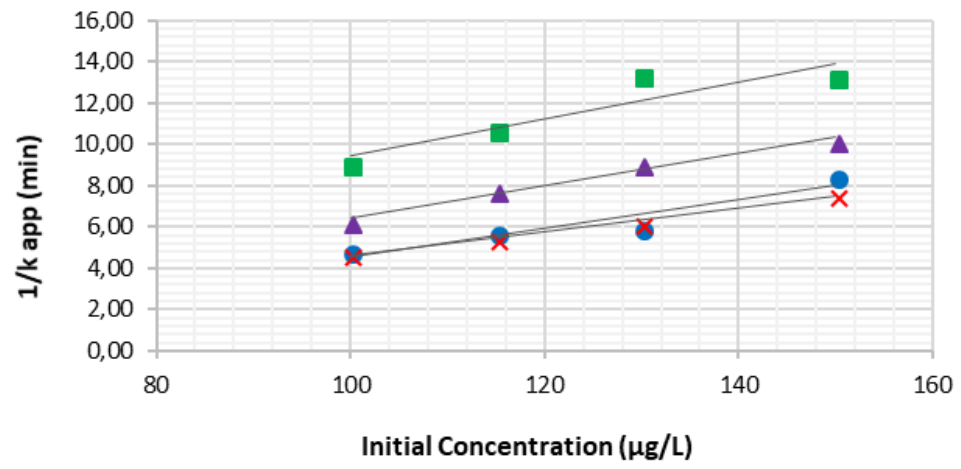

$$
\begin{array}{cc}
y=0,0689 x-2,3136 & \\
R^{2}=0,9095 & \text { FLT } \\
y=0,0569 x-1,0815 & \\
R^{2}=0,9938 & \text { x PYR } \\
y=0,0898 x+0,4529 & \\
R^{2}=0,8418 & \\
y=0,0784 x-1,387 & \\
R^{2}=0,9836 & \Delta \text { DDT }
\end{array}
$$

Figure 6. Linearization of Langmuir-Hinshelwood model

\section{Conclusion}

This research was focused on the heterogeneous photocatalysis process used to treat harvested rainwater in order to make use of it as an alternative source of drinking water.

- The polycyclic aromatic hydrocarbons (PAHs) and organochlorine pesticides (OCPs) in rainwater were chosen to be investigated in this study.

- The rainwater characterization results revealed that PAHs (NAP, FLT, and PYR) were more predominant in industrial and urban residential areas, whereas OCPs (LIN and DDT) were found to contaminate more on the agricultural and rural residential areas.

- Central composite design with response surface methodology was used to evaluate the relationships between operating variables for $\mathrm{TiO}_{2}$ dosage, $\mathrm{pH}$, and and initial concentration to identify the optimum operating conditions.

- Quadratic models for FLT, PYR, LIN, and DDT prove to be significant with low probabilities $(<0.0001)$.

- The obtained optimum conditions included $\mathrm{pH}$ (7), $\mathrm{TiO}_{2}$ concentration (1.54 g/L), and initial concentration $(125 \mu \mathrm{g} / \mathrm{L})$.

- The maximum removal rates were for FLT (88\%), PYR (90\%), LIN (66\%), and DDT (79\%).

- The polycyclic aromatic hydrocarbons (PAHs) and organochlorine pesticides (OCPs) removal rates correspond well with the predicted models.

- $\quad$ The photo-degradation process of PAHs (FLT and PYR) and OCPs (LIN and DDT) followed pseudo first order rate of reaction through L-H kinetic model.

- The proposed treatment process achieved higher degradation efficiencies for FLT, PYR, LIN, and DDT.

\section{ACKNOWLEDGEMENT}

The authors would like to acknowledge Universiti Sains Malaysia (USM) for providing the fund for this study under grant RU (i); 1001/PAWAM/814193, MyBrain15 and also Centre of Drug Research, USM Main Campus, for providing the laboratory testing and facilities.

\section{REFERENCES}

Abbasi T., and Abbasi S.A. (2011), Sources of Pollution in Rooftop Rainwater Harvesting Systems, Critical Reviews in Environmental Science and Technology, 41, 2097-2167.

Abdulla, Fayez A. and Al-Shareef a.W. (2009), Roof Rainwater Harvesting Systems for Household Water Supply, Desalination, 243, 1-3.

Adlan M.N., Puganeshwary P. and Hamidi A.A. (2011), Optimization of Coagulation and Dissolved Air Flotation (DAF) Treatment, Desalination, 277, 1-3.

Aghaie E., Pazouki M., Hosseini M.R., Ranjbar M. and Ghavipanjeh F. (2009), Response Surface Methodology (RSM) Analysis, Chemical Engineering Journal, 147, 245-251.

Ahmad A.A. and Hameed B.H. (2010), Real Textile Wastewater, Journal of Hazardous Materials, 173, 487-493.

Ahmed S., Rasul M.G., Brown R. and Hashib M. (2011), The Heterogeneous Photocatalytic Degradation of Pesticides and Phenolic Contaminants in Wastewater, Journal of Environmental Management, 92, 311-330.

Aljuboury D.D.A., Palaniandy P., Abdul Aziz H.B. and Feroz S. (2016), The Petroleum Treatment, Environmental Earth Sciences, 75, 1-12.

Al-Rasheed R. (2005), Water Treatment by Heterogeneous Photocatalysis, $4^{\text {th }}$ SWCC Acquired Experience Symposium, 114.

Ananpattarachai J. and Puangrat K. (2015), Photocatalytic Degradation of DDT Using Interstitial N-Doped $\mathrm{TiO}_{2}$, Journal of Environmental Science and Health, 50, 247-260.

Bahnemann D. (2004), Photocatalytic Water Treatment, Solar Energy, 77, 445-459.

Baran W., Andrzej M. and Wladyslaw W. (2008), The Effect of UV Radiation Absorption of Cationic and Anionic Dye Solutions, Dyes and Pigments, 76, 226-230. 
Begum A. and Gautam S.K. (2011), Application of Photocatalysis for the Degradation of Endocrine Disrupting Chemicals, Indian Journal of Environmental Protection, 1, 1-10.

Bierbaum V.M., Le V. and Snow T.P. (2011), PAHs and the Chemistry of the ISM, EAS Publications Series, 46, 427-440.

Carolina A., Nedio J. W., Ana P.D., Marcia V. and Lacerda S. (2015), Additive and Antagonistic Effects of Fruit Mixtures on Total Antioxidant Capacities and Bioactive Compounds in Tropical Fruit Juices, Journal of Agricultural and Food Chemistry, 65, 119-27.

Che-Ani A.I., Shaari N., Sairi A., Zain M.F.M. and Tahir M.M. (2009), Rainwater Harvesting as an Alternative Water Supply in the Future, European Journal of Scientific Research, 34, $132-140$.

Chong M.N., Bo J., Christopher W.K.C. and Chris S. (2010), Recent Developments in Photocatalytic Water Treatment Technology: A Review, Water Research, 44, 2997-3027.

Cicek E, Cojocaru C., Zakrzewska-Trznadel, G., Jaworska A. and Harasimowicz M. (2008), Cobalt Removal Using Isparta Pumice and Zeolite 4A Adsorbents, Nukleonika, 53, 121-128.

Dbrowski B., Adriana Z. and Jan Hupka N.D. (2009), Enhanced Photocatalysis, 4, 419-423.

Djoki V., Jelena V., Aleksandar M., Rada P., Djordje J., Antonije O., and Duan M. (2012), A Study of the Photocatalytic Degradation of the Textile Dye $\mathrm{Cl}$ Basic Yellow, Journal of the Serbian Chemical Society, 77, 1747-1757.

Evans C., Coombes P.J. and Dunstan R.H. (2006), Wind, Rain and Bacteria: The Effect of Weather on the Microbial Composition of Roof-Harvested Rainwater, Water Research, 40, 37-44.

Foster H., Iram B.D., Sajnu V. and Alex S. (2011), Photocatalytic Disinfection Using Titanium Dioxide, Applied Microbiology and Biotechnology, 90, 1847-1868.

Geng Q.J., Guo Q.J., Cao C.Q. and Wang H. Q. (2008), Investigation into Photocatalytic Degradation of Gaseous Benzene in a Circulated Photocatalytic Reactor (CPCR), Chemical Engineering and Technology, 31, 1023-1030.

Ghafari S., Hamidi A.A., Mohamed H.I. and Ali A.Z. (2009), Optimization Coagulation-Flocculation Treatment of Leachate, Journal of Hazardous Materials, 163, 650-656.

Hamad H.A., Sadik W.A., Abd El-latif M.M., Kashyout A.B. and Feteha M.Y. (2016), Kinetic Study for Degradation of Dichlorophenol-Indophenol (DCPIP) Dye Using Highly Active Mesoporous $\mathrm{TiO}_{2}$ Nanoparticles, Journal of Environmental Sciences, 43, 26-39.

Haritash A.K. and Kaushik C. P. (2009), Biodegradation Aspects of Polycyclic Aromatic Hydrocarbons (PAHs): A Review, Journal of Hazardous Materials, 169, 1-15.

He J. and Rajasekhar B. (2009), A Study of Precipitation Scavenging of Semivolatile Organic Compounds in a Tropical Area, Journal of Geophysical Research Atmospheres, 114, 1-10.

Jang S.J., Moon S.K. and Byung W.K. (2005), Photodegradation of DDT with the Photodeposited Ferric lon on the $\mathrm{TiO}_{2}$ Film, Water Research, 39, 2178-2188.

Jo M.S., Eldon R.R., Soo H.K. and Hung S.P. (2008), An Analysis of Synergistic and Antagonistic Behavior during BTEX Removal, Journal of Hazardous Materials, 152, 1276-1284.

Katz A., Andrew M., Leonard T. and Ho K.S. (2015), Fouling and Inactivation of Titanium Dioxide-Based Photocatalytic Systems, Critical Reviews in Environmental Science and Technology, 45, 1880-1915.
Khezrianjoo S. and Revanasiddappa H. (2012), LangmuirHinshelwood Kinetic Expression for the Photocatalytic Degradation of Metanil Yellow Aqueous Solutions by $\mathrm{ZnO}$ Catalyst, Chemical Sciences Journal, 2012, 81-85.

Kim R., Sangho L., Jung-hun L. and Young-min K. (2005), A Rainwater Harvesting Technology by Roof Coating Using $\mathrm{TiO}_{2}$, Materials Science Forum, 486-487, 17-20.

Konstantinou, loannis K. and Triantafyllos A. (2004), $\mathrm{TiO}_{2}$-Assisted Photocatalytic Degradation of Azo Dyes, Applied Catalysis B: Environmental, 49, 1-14.

Lair A., Corinne F., Jean M.C. and Jean M.H. (2008), Naphthalene Degradation in Water by Heterogeneous Photocatalysis, Journal of Photochemistry and Photobiology A: Chemistry, 193, 193-203.

Lam S.M., Jin C.S. and Abdul Rahman M. (2010), Photocatalytic Degradation of Phenol Using $\mathrm{TiO}_{2}-\mathrm{P} 25 /$ activated Carbon (AC), Korean Journal of Chemical Engineering, 27, 1109-1116.

Li L., Wanpeng Z., Le C., Pengyi Z. and Zhongyin C. (2005), Photocatalytic Ozonation of Dibutyl Phthalate over $\mathrm{TiO}_{2}$ Film, Journal of Photochemistry and Photobiology A: Chemistry, 175, 172-177.

Liga M.V., Samuel J.M., Huma R.J., Andrew R.B. and Qilin L. (2013), Silica Decorated $\mathrm{TiO}_{2}$ for Virus Inactivation in Drinking Water, Environmental Science and Technology, 47, 6463-6470.

Liu B., Bing C., Bai Y.Z., Liang J., He Z. and Kenneth L. (2016), Photocatalytic Degradation of Polycyclic Aromatic Hydrocarbons in Offshore Produced Water, Journal of Environmental Engineering, 04016054.

Luo Z., Chuan-Ling W., Nan-nan H., Zhi-Guo S., Hui-Xin L. and Dan C. (2015a), Correlation between the Photocatalytic Degradability of PAHs over Pt $/ \mathrm{TiO}_{2}-\mathrm{SiO}_{2}$ in Water and Their Quantitative Molecular Structure, Journal of Nanomaterials, 1, 1-11.

Mahmoodi V. and Javad S. (2014), Optimization of Photocatalytic

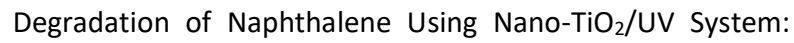
Statistical Analysis by a Response Surface Methodology, Desalination and Water Treatment, 52, 6664-6672.

Malato S., Fernandez-Ibanez P., Maldonado M.I., Blanco J. and Gernjak W. (2009), Decontamination and Disinfection of Water by Solar Photocatalysis: Recent Overview and Trends, Catalysis Today, 147, 1-59.

Meera V. and Mansoor A. (2006), Water Quality of Rooftop Rainwater Harvesting Systems: A Review, Journal of Water Supply, 55, 257-268.

Miguntanna N.S., Egodawatta P. and Goonetilleke A. (2010), Pollutant Characteristics on Roof Surfaces for Evaluation as a Storm water Harvesting Catchment, Desalination and Water Treatment, 19, 205-211.

Milena S. and Lopez Z. (2013), Synthesis and Characterization of Modified $\mathrm{TiO}_{2}$ for the Photo - Treatment of Wastewater with Visible Light. Master Thesis, Universidad Nacional de Colombia.

Muneer M., Qamar M., Saquib M. and Bahnemann D.W. (2005), Heterogeneous Photocatalysed Reaction of Three Selected Pesticide Derivatives, Propham, Propachlor and Tebuthiuron in Aqueous Suspensions of Titanium Dioxide, Chemosphere, 61, 457-468.

Online I.P., Omid B., Majid A. and Bio J. (2014), Photocatalytic Degradation of Malachite Green in Aqueous Solution Using $\mathrm{TiO}_{2}$ Nanocatalyst, Environment Science, 5, 301-310. 
Pang W., Nai-yun G., Yang D. and Yu-lin T. (2009), Novel Photocatalytic Reactor for Degradation of DDT in Water and Its Optimization Model, Journal of Zhejiang University SCIENCE A, 10, 732-738.

Pekey B., Duran K. and Savas A. (2007), Atmospheric Deposition of Polycyclic Aromatic Hydrocarbons, Chemosphere, 67, 537-547.

Polkowska Z., Górecki T. and Namieśnik J. (2002), Quality of Roof Runoff Waters, Chemosphere, 49, 1275-1283.

Ponce de Leon C., Huerta R., Sommer I., Rojo, F., Moya M., Hernandez M. and Rosas I. (2014) Polycyclic Aromatic Hydrocarbons in Rainwater, Polycyclic Aromatic Compounds, 34, 69-88.

Reza K.M., Kurny A.S.W. and Fahmida G. (2015), Parameters Affecting the Photocatalytic Degradation of Dyes Using $\mathrm{TiO}_{2}$ : A Review, Applied Water Science, 1-10.

Robertson, Peter K. J., Jeanette M. C., Robertson, and Detlef W.B. (2012), Removal of Microorganisms from Water Using Semiconductor Photocatalysis, Journal of Hazardous Materials, 211, 161-171.

Rubio-Clemente A., Ricardo A., Torres-Palma and Gustavo A.P. (2014), Removal of Polycyclic Aromatic Hydrocarbons by Chemical Treatments: A Review, Science of the Total Environment, 478, 201-225.

Sahu J.N., Jyotikusum A. and Meikap B.C. (2010), Optimization of Production Conditions for Activated Carbons from Tamarind Wood by Zinc Chloride, Bioresource Technology, 101, 1974-1982.

Saquib M., Abu Tariq M., Faisal M. and Muneer M. (2008), Photocatalytic Degradation of Two Selected Dye Derivatives, Desalination, 219, 301-311.

Sazakli E., Alexopoulos and Leotsinidis M. (2007), Rainwater Harvesting, Quality Assessment, Water Research, 41, 2039-2047.

Senthilnathan J. and Ligy P. (2010), Removal of Mixed Pesticides Using Surfactant-Assisted Nano-TiO ${ }_{2}$, Water, Air, and Soil Pollution, 210, 143-154.

Sharma S., Anushree M. and Santosh S. (2009), Optimization of Nutrient Supplementation for $\mathrm{Cr}(\mathrm{VI})$ Removal by Aspergillus Lentulus AML05, Journal of Hazardous Materials, 164, 1198-1204.

Silva A.M.T., Nouli E., Xekoukoulotakis N.P. and Dionissios M. (2007), $\mathrm{H}_{2} \mathrm{O}_{2}$-Assisted $\mathrm{TiO}_{2}$ Photocatalytic Treatment of Simulated and Actual Olive Mill Wastewaters, Applied Catalysis B: Environmental, 73, 11-22.

Tan I.A.W, Ahmad A.L. and Hameed B.H. (2008), Preparation of Activated Carbon from Coconut Husk, Journal of Hazardous Materials, 153, 709-17.

Uyguner-Demirel C.S. and Bekbolet M. (2011), Natural Organic Matter in Relation to Photocatalytic Oxidation, Chemosphere, 84, 1009-1031.

Wang J.L., Che W., Li J.Q., Pan G.Q. and Yi H.X. (2009), IRCSA Conference, Kuala Lumpur, Malaysia, 86, 1-6.

Wang Le, Hongwei W., Yingju F., Xinzheng L. and Jinhua Z. (2009), Synthesis, Optical Properties, and Photocatalytic Activity of One-Dimensional Core-Shell Nanocomposites, Nanoscale Research Letters, 4, 558-564.

Zinatizadeh A.A.L., Mohamed A.R., Mashitah M.D., Abdullah A.Z. and Hasnain I.M. (2007), Pre-Treated Palm Oil Mill Effluent Digestion, Biochemical Engineering Journal, 35, 226-237. 